\title{
Nitrogênio disponível ao milho: Crescimento, absorção e rendimento de grãos ${ }^{1}$
}

\author{
Solange França², João Mielniczuk ${ }^{3}$, Luís M. G. Rosa ${ }^{4}$, \\ Homero Bergamaschi ${ }^{4} \&$ João I. Bergonci ${ }^{5}$
}

\begin{abstract}
RESU M O
Este trabalho visou quantificar o nitrogênio (N) disponível ao milho e avaliar seu efeito sobre o índice de área foliar (IAF), a produção de massa seca da parte aérea (M SPA), o $\mathrm{N}$ absorvido pela parte aérea e 0 rendimento de grãos. As avaliações foram realizadas aos 52, 65, 74, 82, 99 e 160 dias após a emergência (DAE) em um experimento de manejo de solo conduzido em plantio direto desde 1985, com os sistemas de culturas de aveia/milho $(A / M)$, aveia + ervilhaca/milho + caupi $(A+E / M+C)$ e ervilhaca/milho (E/M) e duas doses de $\mathrm{N}\left(0 \mathrm{~N}\right.$ e $180 \mathrm{~N}-\mathrm{kg} \mathrm{ha}^{-1}$ ) aplicadas no milho, na forma de uréia. $\mathrm{Na}$ safra 2000/01 foram aplicadas doses de 0,60, 120 e $180 \mathrm{~kg} \mathrm{ha}^{-1}$ de N. O N estimado disponível ao milho e calculado a partir da contribuição do solo, plantas de cobertura e do adubo nitrogenado, variou de 27 a $192 \mathrm{~kg} \mathrm{ha}^{-1}$, sendo os menores valores associados aos tratamentos apenas com gramíneas ( $A / M)$ e os maiores aos com $N$ e presença de leguminosas no sistema $(E / M$ e $A+E / M+C)$. Todas as variáveis avaliadas apresentaram alta dependência do $\mathrm{N}$ disponível e tiveram seus valores maximizados próximos da maior disponibilidade de $\mathrm{N}\left(192 \mathrm{~kg} \mathrm{ha}^{-1}\right)$. Com esta disponibilidade foram observados, no estadio de polinização (65 DAE), o maior IAF $(4,41)$ e a mais alta concentração de $N$ na folha índice $(2,49 \%)$, enquanto o maior acúmulo de $\mathrm{N}$ na parte aérea foi constatado no estádio de grão leitoso (74 DAE) e o acúmulo de MSPA no estádio de grão dentado (99 DAE). O rendimento máximo de grãos atingido foi de $8.920 \mathrm{~kg} \mathrm{ha}^{-1}$, correspondendo a uma exportação de $\mathrm{N}$ pelo grão, de $112 \mathrm{~kg} \mathrm{ha}^{-1}$.
\end{abstract}

Palavras-chave: sistemas de cultura, índice de área foliar, matéria seca da parte aérea, teor de nitrogênio, Zea mays L.

\section{Nitrogen available to maize: Absorption, growth and yield}

\begin{abstract}
This w ork aimed to quantify the available nitrogen (N) to a maize crop and evaluate its effects on leaf area index (LAI), shoot dry matter (SDM) production, $\mathrm{N}$ absorption by the above ground biomass, and grain yield. The evaluations were performed in a soil management experiment run since 1985, with three cropping systems (oat - Avena strigosa/maize, oat + vetch - Vicia sativa/maize and oat + vetch/maize + cowpea - Vigna unguiculata) and two rates of nitrogen ( 0 and $\left.180 \mathrm{~kg} \mathrm{ha}^{-1}\right)$ applied to maize. In the $2000 /$ 2001 cropping year, four nitrogen rates were applied $\left(0,60,120\right.$ and $\left.180 \mathrm{~kg} \mathrm{ha}^{-1}\right)$. The estimated available $\mathrm{N}$ to the maize calculated from the contribution from the soil, cover crops and $\mathrm{N}$ fertilizer varied from 27 to $192 \mathrm{~kg} \mathrm{ha}^{-1}$. All evaluated variables presented high dependence on available $\mathrm{N}$, and reached its maximum level near to the highest level of available $\mathrm{N}\left(192 \mathrm{~kg} \mathrm{ha}^{-1}\right)$. With this level of availability, at the stage of pollination, the largest values of LAI (4.41) and the highest leaf N concentration were observed, however, the highest $\mathrm{N}$ accumulation in the above ground biomass was observed at the milk grain stage and the shoot dry matter accumulation at the dent stage. The maximum grain yield obtained was 8,920 $\mathrm{kg} \mathrm{ha}^{-1}$, corresponding to $112 \mathrm{~kg} \mathrm{ha}^{-1}$ of exported $\mathrm{N}$ by the grain.
\end{abstract}

Key words: cropping systems, leaf area index, shoot dry matter, biomass nitrogen concentration, Zea mays L.

\footnotetext{
1 Parte da Tese de Doutorado do primeiro autor apresentada ao Programa de Pós-Graduação em Fitotecnia da UFRGS

2 Departamento de Ciências Agrárias e Ambientais/U ESC. Rod. Ilhéus/Itabuna, Km 16, CEP 45650-000, Ilhéus, BA. Fone: (73) 3680-5112. E-mail: solafranca@yahoo.com.br

${ }^{3}$ Departamento de Solos/UFRGS, Caixa Postal 776, CEP 90.001-970, Porto Alegre, RS. Fone: (51) 3316-6017. E-mail: joaomiel@terra.com.br. Bolsista do CN Pq ${ }^{4}$ Departamento de Plantas Forrageiras e Agrometeorologia/U FRGS, C.P. 15100, CEP 91501-970, Porto Alegre, RS. Fone: (51) 3308-7463 e $3308-6255$. E-mail: Imrosa@ufrgs.br; homerobe@ufrgs.br. Bolsista do CNPq

${ }^{5}$ D epartamento de Botânica/U FRGS. Rua Paulo Gama s/n, CEP 90043-900, Porto Alegre, RS. Fone: (51) 3308-7687. E-mail: joao.bergonci@ufrgs.br
} 


\section{INTRODUÇÃO}

Normalmente, o nitrogênio (N) é um elemento suprido em quantidade insuficiente pelo solo, em especial para gramíneas de alta produtividade, como o milho, razão por que devem ser utilizadas fontes adicionais de $\mathrm{N}$, como as leguminosas e a adubação mineral (Ceretta et al., 1994; Teixeira et al., 1994; Amado \& Mielniczuk, 2000). Segundo Silva et al. (2007) com a evolução do sistema de semeadura direta novas técnicas de manejo são exigidas para aumentar o rendimento de grãos de milho sem elevar o custo de produção, entre as quais está o uso de espécies de cobertura de solo no inverno, com capacidade de fixação e/ou reciclagem de nutrientes que confiram maior proteção ao solo.

O estoque de $\mathrm{N}$ total do solo pode ser recuperado no sistema plantio direto salientando-se, entretanto, a importância das espécies leguminosas com alta produção de resíduos vegetais nos sistemas de cultura e da adubação nitrogenada, que contribuem para a manutenção dos estoques de $\mathrm{N}$ total e de carbono orgânico total (COT) do solo, para a qualidade do solo e do ambiente e para a produtividade do milho (Lovato et al., 2004).

Métodos têm sido propostos visando a melhoraria da administração de $\mathrm{N}$ e, simultaneamente, ao aumento de produtividade com a proteção do meio ambiente, diminuindo a concentração de nitratos no solo e na água (Souza et al., 2009). A utilização de leguminosas nos sistemas de produção vem ao encontro da crescente preocupação com os efeitos do uso indiscriminado de fontes minerais de nitrogênio sobre o ambiente, despertando o interesse pela utilização de adubos verdes como culturas de proteção do solo e fonte alternativa de $\mathrm{N}$ para as culturas, constituindo-se na prática de manejo por meio da qual se procura preservar a qualidade do ambiente sem prescindir da obtenção de produtividade elevada pelas culturas (Arf et al., 1999). O N é um dos elementos que mais contribuem para a contaminação de lençóis freáticos além de responsável por grande parte do gasto com adubação; desta forma, a utilização de leguminosas em arranjos espaciais (consórcios) ou temporais (rotações) pode colaborar para reduzir ou até mesmo eliminar esses custos (Assmann et al., 2003).

Dentro desta visão de manejo da adubação nitrogenada o conhecimento da estimativa das quantidades de nitrogênio disponibilizadas pelas leguminosas é fundamental para que se determine a quantidade de $\mathrm{N}$ a ser complementada via fertilizante mineral, seguindo-se critérios de produtividade, retorno econômico e preservação ambiental (Amado et al., 2000). A magnitude de substituição da adubação nitrogenada mineral do milho pelas leguminosas de inverno depende de diversos fatores dentre os quais se pode destacar a quantidade de $\mathrm{N}$ acumulado pelas leguminosas, a velocidade e o sincronismo com que o nutriente é liberado dos resíduos culturais, a disponibilidade de $\mathrm{N}$ do solo, o potencial de rendimento do milho e o nível tecnológico empregado (Aita et al., 2001).

A inclusão de outros atributos que exerçam influência sobre a disponibilidade de nitrogênio, além do teor de matéria orgânica, como o sistema de preparo e a cultura de cobertura antecedente, pode permitir o aprimoramento da recomendação de adubação nitrogenada. Dentre as informações requeridas para otimizar esta recomendação se incluem: (a) a estimativa do potencial de mineralização do $\mathrm{N}$ do solo; (b) a quantidade de N mineralizado ou imobilizado pela cultura de cobertura; (c) o requerimento do $\mathrm{N}$ pela cultura, para atingir um rendimento projetado; (d) a expectativa da eficiência de recuperação do $\mathrm{N}$ disponível das diferentes fontes (solo, cultura de cobertura e fertilizante mineral) (Amado, 1997).

Objetivou-se, com este estudo, quantificar o nitrogênio disponível ao milho em diferentes sistemas de cultura e doses de $\mathrm{N}$ mineral e avaliar seu efeito sobre o índice de área foliar, a produção de massa seca da parte aérea, o $\mathrm{N}$ absorvido, o teor de $\mathrm{N}$ na folha índice e o rendimento de grãos.

\section{Material e MÉTODOS}

O estudo foi conduzido em um experimento de longa duração implantado em 1985, na Estação Experimental Agronômica da Universidade Federal do Rio Grande do Sul (EEA/UFRGS), em Eldorado do Sul, RS ( $30^{\circ} 05^{\prime} \mathrm{S}, 51^{\circ} 39^{\prime} \mathrm{W}, 46 \mathrm{~m}$ altitude). As avaliações foram realizadas na safra 2000/01 (França, 2003), em sistema plantio direto (PD), num Argissolo Vermelho distrófico típico (EMBRAPA, 1999). Em análise química do solo na profundidade de $0-0175 \mathrm{~m}$, realizada em 2003, obtiveram-se os seguintes resultados: $\mathrm{pH}=4,80 ; \mathrm{P}=47 \mathrm{ppm} ; \mathrm{K}=120 \mathrm{ppm}, \mathrm{Ca}$ $=3,60 ; \mathrm{Mg}=2,77 ; \mathrm{Al}=0,46 \mathrm{cmolc} \mathrm{kg}^{-1}$ de solo e $\mathrm{MO}=2,4 \%$ (Zanatta, 2006). O clima da região, de acordo com a classificação climática de Köeppen, é subtropical úmido de verão quente do tipo fundamental "Cfa". A precipitação média anual fica em torno de $1.440 \mathrm{~mm}$, com média mensal de $120 \mathrm{~mm}$, sendo que durante o ciclo da cultura do milho (novembro a fevereiro) é de $425 \mathrm{~mm}$. A temperatura média anual é de $19,2^{\circ} \mathrm{C}$ (Bergamaschi et al., 2003).

O delineamento experimental utilizado foi de blocos casualizados (15 x 20 m), com os sistemas de cultura distribuídos nas parcelas principais $(5 \times 20 \mathrm{~m})$ e as doses de $\mathrm{N}$ aplicadas em faixas $(15 \times 5 \mathrm{~m})$. Os tratamentos foram constituídos por sistemas de cultura A/M - aveia (Avena strigosa)/milho (Zea mays), E/ $\mathrm{M}$ - ervilhaca (Vicia sativa)/milho e $\mathrm{A}+\mathrm{E} / \mathrm{M}+\mathrm{C}-$ aveia + ervilhaca/milho + caupi (Vigna unguiculata); nesta safra foram aplicadas as doses de $0,60,120 \mathrm{e} 180 \mathrm{~kg} \mathrm{ha}^{-1}$ de $\mathrm{N}$ mineral, de forma que as doses de 0 e $60 \mathrm{~kg} \mathrm{ha}^{-1}$ coincidiram com as parcelas que, historicamente, não receberam $\mathrm{N}(0 \mathrm{~N})$ e as de 120 e 180 $\mathrm{kg} \mathrm{ha}^{-1}$ nas parcelas com aplicações históricas anuais de 180 $\mathrm{kg} \mathrm{ha}^{-1}$ de N (180 N). A implantação da aveia e ervilhaca ocorreu em abril e a do milho em outubro, utilizando-se o híbrido Pioneer 32R21 com espaçamento entre linhas de $0,90 \mathrm{~m}$ e uma população de 69.000 plantas ha ${ }^{-1}$. As doses de $\mathrm{N}$ mineral constituíram os sub-blocos cuja aplicação, a lanço ao lado da linha de milho, foi de um terço do $\mathrm{N}$ mineral quando o milho apresentava quatro folhas expandidas e dois terços com oito folhas expandidas. A adubação de base utilizada foi de $250 \mathrm{~kg} \mathrm{ha}^{-1}$ da formulação 520-20. O caupi foi plantado em covas nas entrelinhas do milho, aproximadamente 30 dias após a emergência do milho.

A estimativa do $\mathrm{N}$ disponível (Nd) para o milho em relação aos sistemas de cultura foi baseada na Eq.1, representando a média dos últimos dois anos: 


$$
\begin{gathered}
\mathrm{Nd}=\mathrm{Nt} \text { solo } * \mathrm{k}_{1}+\left(5,066+\mathrm{k}_{2} * \mathrm{Nr}-\right. \\
-0,242 * \operatorname{Rel~C/N})+\mathrm{k}_{3} * \mathrm{Nf}
\end{gathered}
$$

em que:

$\mathrm{k}_{1}, \mathrm{k}_{2}$ e $\mathrm{k}_{3}$ - coeficientes de eficiência do $\mathrm{N}$ total $(\mathrm{Nt})$ contido no solo, na camada de $0-0,175 \mathrm{~m}$, resíduo de plantas de cobertura (Nr) e aplicado como fertilizante (Nf), respectivamente (Amado, 1997). Segundo o autor, $\mathrm{k}_{1}$ assume o valor de 0,011 no plantio direto, $\mathrm{k}_{2}$ é igual a 0,1334 e $_{3}$ é igual a 0,50. Utilizaram-se o Nt do solo e o $\mathrm{N}$ nos resíduos, determinados pela média dos 13 anos de duração do experimento, por Lovato (2001) e a relação C/N determinada por Amado (1997). Segundo Amado (1997) e Amado \& Mielniczuk (2000), o coeficiente $\mathrm{k}_{3} \mathrm{e}$ de 50\%; no entanto, para Araújo et al. (2004) e Villas-Bôas et al. (2005), a eficiência no uso do fertilizante nitrogenado variou de 39 a $74 \%$. Na presente pesquisa adotou-se o coeficiente de 0,75 tendo em vista que o suprimento de água foi mantido adequado durante todo o ciclo da cultura mediante irrigações por aspersão.

Realizaram-se cinco amostragens para avaliação do índice de área foliar (IAF), de massa seca da parte aérea (MSPA) e do teor de $\mathrm{N}$ na planta. As determinações foram realizadas aos 52, 65, 74, 82 e 99 dias após a emergência (DAE), correspondendo aos estádios 3 (doze folhas completamente expandidas), 5 (período de polinização), 6 (grão leitoso), 7 (grão pastoso) e 9 (grão dentado), da escala proposta por Hanway (1963), respectivamente. Até a avaliação, realizada aos 82 DAE, analisou-se a planta inteira (colmos, folhas e espigas) e aos 99 DAE realizou-se a separação da espiga buscando-se quantificar o $\mathrm{N}$ que estava sendo translocado da planta para o grão.

O índice de área foliar foi determinado através da medição da área foliar verde, feita em planímetro ótico, modeloLI 3000 (Licor, Lincoln, EUA), em três plantas por repetição de cada um dos três sistemas de cultura e nas quatro doses de N. O IAF de cada amostra foi calculado através da divisão da área foliar verde da amostra $\left(\mathrm{m}^{2}\right)$ pela área do terreno ocupada pela amostra $\left(\mathrm{m}^{2}\right)$.

A massa seca da parte aérea foi determinada utilizando-se as mesmas plantas através das quais se determinou o IAF. O material foi colocado em estufa com circulação de ar forçada, em temperatura de aproximadamente $70^{\circ} \mathrm{C}$, até atingir peso constante. Essas mesmas amostras serviram para a determinação do teor de $\mathrm{N}$ na planta, realizada a partir da análise de tecido vegetal, utilizando-se o método de Kjeldahl, descrito em Tedesco et al. (1995). O conteúdo de $\mathrm{N}$ absorvido na planta foi obtido multiplicando-se a massa seca da parte aérea $\left(\mathrm{kg} \mathrm{ha}^{-1}\right)$ pelo teor de $\mathrm{N}$ na planta.

No estádio de pleno florescimento, caracterizado pela emissão dos estigmas do milho e de polinização (65 DAE), foram coletadas quatro plantas e quatro folhas índice (primeira inferior e oposta à espiga principal) na área útil de cada subparcela para determinar o teor de $\mathrm{N}$ e o rendimento da fitomassa aérea.

O rendimento de grãos foi avaliado mediante a colheita manual, aos $160 \mathrm{DAE}$, em área central de $6,3 \mathrm{~m}^{2}$ por parcela. As espigas foram debulhadas mecanicamente, os grãos pesados e subamostrados, para determinação do teor de N no grão e da umidade. Os resultados do rendimento de grãos foram corrigidos para $13 \%$ de umidade.
Visando atenuar o efeito do déficit hídrico durante o ciclo do milho, aplicaram-se irrigações suplementares durante todo o ciclo, quando a precipitação era insuficiente para atender à demanda hídrica da cultura, utilizando-se um sistema de irrigação por aspersão.

Os dados de $\mathrm{N}$ disponível, $\mathrm{N}$ absorvido e teor de $\mathrm{N}$ na folha índice versus rendimento de grãos e $\mathrm{N}$ absorvido versus $\mathrm{N}$ disponível, foram analisados por regressão linear (SAS, Carry, EUA), segundo a metodologia GLM (Freud et al., 1986). As superfícies de resposta entre IAF, MSPA e $\mathrm{N}$ absorvido pela planta versus $\mathrm{N}$ disponível e dias após a semeadura, foram calculadas utilizando-se o modelo gaussiano do pacote gráfico Sigmaplot v.8.0.

\section{RESULTADOS E DISCUSSÃO}

\section{Nitrogênio disponível}

A presença de leguminosas no sistema resultou em maior disponibilidade de $\mathrm{N}$ em comparação com os sistemas constituídos de gramíneas, independente da dose residual de $\mathrm{N}$, aplicada ao milho na presente safra. O tratamento com menor quantidade de nitrogênio disponível foi $\mathrm{A} / \mathrm{M} 0 \mathrm{~N}$, correspondendo a $27 \mathrm{~kg} \mathrm{ha}^{-1}$, e os tratamentos E/M $180 \mathrm{~N} \mathrm{e}$ $\mathrm{A}+\mathrm{E} / \mathrm{M}+\mathrm{C} 180 \mathrm{~N}$ foram os que apresentaram as maiores quantidades, isto é, de 190 e $192 \mathrm{~kg} \mathrm{ha}^{-1}$ de $\mathrm{N}$ disponível, respectivamente (Tabela 1 ).

Os valores de $\mathrm{N}$ disponível refletem a quantidade de $\mathrm{N}$ total no solo, a relação $\mathrm{C} / \mathrm{N}$ das plantas de cobertura e a dose de $\mathrm{N}$ fertilizante aplicada (Tabela 1). A adubação nitrogenada em cobertura promoveu acréscimos no $\mathrm{N}$ disponível. A dose de $\mathrm{N}$ mineral aplicada nos anos que precederam esta pesquisa influenciou o estoque de $\mathrm{N}$ total no solo e de $\mathrm{N}$ nos resíduos culturais.

Para Lovato et al. (2004), a aplicação de N mineral aumentou o estoque de $\mathrm{N}$ total nas camadas de 0-0,175 e 0,175-0,30 m e os sistemas de cultura $\mathrm{E} / \mathrm{M}$ e $\mathrm{A}+\mathrm{E} / \mathrm{M}+\mathrm{C}$, pela presença de leguminosas, promoveram maior acúmulo de $\mathrm{N}$ total em relação ao sistema $\mathrm{A} / \mathrm{M}$. O N dos resíduos também foi menor no sistema de cultura $\mathrm{A} / \mathrm{M}$, em que a adição de $\mathrm{N}$ por meio dos resíduos culturais se limitou à reciclagem de N. Segundo Amado et al. (2000) nos sistemas com presença de leguminosas (E/M ou $\mathrm{A}+\mathrm{E} / \mathrm{M}+\mathrm{C}$ ) ocorreu, além do efeito de reciclagem, aporte de $\mathrm{N}$ oriundo da fixação simbiótica do $\mathrm{N}_{2}$ atmosférico pelas leguminosas. De acordo com Weber \& Mielniczuk (2009), a quantidade estimada de $\mathrm{N}$ fixado pelas leguminosas em 22 anos nesta área experimental, variou de 800 a $1.980 \mathrm{~kg} \mathrm{ha}^{-1}$, com as maiores quantidades obtidas nos sistemas com leguminosas estivais. A relação $\mathrm{C} / \mathrm{N}$ da massa seca obtida no tratamento $\mathrm{A} /$ $\mathrm{M}$ foi de 47 , bem superior àquela obtida no tratamento $\mathrm{E} / \mathrm{M}$, que foi de 14 e na consorciação $(\mathrm{A}+\mathrm{E} / \mathrm{M}+\mathrm{C})$, que foi de 30 . Conforme Aita et al. (2001), a relação C/N de 30 aproxima-se do valor de equilíbrio entre os processos de mineralização e imobilização. $\mathrm{O}$ tratamento $\mathrm{A}+\mathrm{E} / \mathrm{M}+\mathrm{C}$, além de apresentar características interessantes, como produzir uma quantidade de massa seca tão elevada quanto aquela obtida com o cultivo da aveia isolada e acumular $\mathrm{N}$ na fitomassa semelhante à da ervilhaca isolada, apresenta uma quantidade maior de $\mathrm{N}$ total 
Tabela 1. Nitrogênio ( $\mathrm{N}$ ) disponível ao milho em função de diferentes sistemas de cultura e doses de nitrogênio mineral

\begin{tabular}{|c|c|c|c|c|c|}
\hline \multirow{2}{*}{ Tratamentos } & $\mathrm{N}$ total no solo ${ }^{1}$ & $\mathrm{~N}$ fitomassa ${ }^{1}$ & \multirow{2}{*}{$\begin{array}{c}\text { Relação } \\
\mathrm{C}^{\prime} \mathbf{N}^{2}\end{array}$} & $\mathrm{~N}$ fertilizante & $\mathrm{N}$ disponível ${ }^{3}$ \\
\hline & \multicolumn{2}{|c|}{$\left(\mathrm{kg} \mathrm{ha}^{-1}\right)$} & & \multicolumn{2}{|c|}{$\left(\mathrm{kg} \mathrm{ha}^{-1}\right)$} \\
\hline $\mathrm{A} / \mathrm{M} O \mathrm{~N}$ & 2551 & 37 & 47 & 0 & 27 \\
\hline$E / M O N$ & 3001 & 114 & 14 & 0 & 50 \\
\hline $\mathrm{A}+\mathrm{E} / \mathrm{M}+\mathrm{CON}$ & 3265 & 156 & 30 & 0 & 55 \\
\hline $\mathrm{A} / \mathrm{M} 60 \mathrm{~N}$ & 2551 & 37 & 47 & 60 & 72 \\
\hline $\mathrm{E} / \mathrm{M} 60 \mathrm{~N}$ & 3001 & 114 & 14 & 60 & 95 \\
\hline$A+E / M+C 60 N$ & 3265 & 156 & 30 & 60 & 100 \\
\hline A/M $120 \mathrm{~N}$ & 3025 & 42 & 47 & 120 & 123 \\
\hline $\mathrm{E} / \mathrm{M} 120 \mathrm{~N}$ & 3553 & 110 & 14 & 120 & 145 \\
\hline$A+E / M+C 120 N$ & 3719 & 134 & 30 & 120 & 147 \\
\hline A/M $180 \mathrm{~N}$ & 3025 & 42 & 47 & 180 & 168 \\
\hline $\mathrm{E} / \mathrm{M} 180 \mathrm{~N}$ & 3553 & 110 & 14 & 180 & 190 \\
\hline$A+E / M+C 180 N$ & 3719 & 134 & 30 & 180 & 192 \\
\hline
\end{tabular}

${ }^{1}$ Lovato (2001); O N total na camada de 0-0175 m;

${ }^{2}$ Amado (1997)

Sistemas de cultura: $\mathrm{A} / \mathrm{M}=$ Aveia/Milho, $\mathrm{V} / \mathrm{M}=$ Vica/Milho, $\mathrm{A}+\mathrm{V} / \mathrm{M}+\mathrm{C}=$ Aveia+ Vica/Milho+ Caupi

Doses de $\mathrm{N}$ mineral: 0, 60, 120 e $180 \mathrm{~kg} \mathrm{ha}^{-1}$

${ }^{3}$ Obtido pela equação ajustada por Amado (1997):

$\mathrm{Nd}=\mathrm{NT}$ solo $* \mathrm{k}_{1}+\left(5,066+\mathrm{k}_{2} * \mathrm{~N}\right.$ resíduo de plantas de cobertura $-0,242 *$ Rel $\left.\mathrm{C} / \mathrm{N}\right)+\mathrm{k}_{3} * \mathrm{~N}$ fertilizante

no solo e na fitomassa. Para Heinrichs et al. (2001), a consorciação de aveia e ervilhaca apresenta, em geral, uma fitomassa com relação $\mathrm{C} / \mathrm{N}$ mais equilibrada do que a proveniente das culturas solteiras, como aveia e ervilhaca.

\section{Índice de área foliar (IAF)}

O índice de área foliar durante o ciclo da cultura apresentou desenvolvimento diferenciado em função da disponibilidade de nitrogênio, constatando-se que os acréscimos na disponibilidade proporcionaram aumentos de IAF (Tabela $2 \mathrm{e}$ Figura 1A). Aos 52 DAE, no estádio de doze folhas o menor IAF foi de 1,29, com disponibilidade de $\mathrm{N}$ de $27 \mathrm{~kg} \mathrm{ha}^{-1}$ e o maior IAF foi de 3,63, com $192 \mathrm{~kg} \mathrm{ha}^{-1} \mathrm{de} \mathrm{N}$. Independentemente do $\mathrm{N}$ disponível, o máximo IAF ocorreu aos $65 \mathrm{DAE}$, no estádio de polinização, com valor de IAF de 4,41, com a maior disponibilidade de N. Posterior ao IAF máximo, nas avaliações realizadas aos 74 DAE, 82 DAE e 99 DAE o mesmo começou a diminuir devido ao processo natural de senescência das folhas. França et al. (1999) relatam para milho na mesma região, IAF máximo de 5,8 no tratamento com irrigação aos 56 DAE (pendoamento) e de 3,6 no tratamento sem irrigação aos 77 DAE (enchimento de grãos). Segundo Lopes et al. (2009) o IAF máximo ocorreu entre 60 e 75 DAE com valores de $6,2 \mathrm{~m}^{2} \mathrm{~m}^{-2}$ no plantio convencional e $4,7 \mathrm{~m}^{2} \mathrm{~m}^{-2}$ no plantio direto mas após os 90 e 105 DAE ocorreu queda na fitomassa seca de folha devida, sem dúvida, ao início da senescência. Para Wolschick et al. (2003), nas plantas que receberam adubação nitrogenada observou-se senescência foliar acelerada a partir dos 90 DAE quando as plantas estavam no estádio de grão farináceo. Neste estádio os grãos contêm em torno de $70 \%$ de água, já tendo acumulado metade da massa seca, sendo a senescência foliar, a partir deste estádio, um processo natural.

\section{Massa seca da parte aérea (MSPA)}

$\mathrm{O}$ acúmulo de massa seca da parte aérea apresentou alto grau de dependência do $\mathrm{N}$ disponível (Tabela 2 e Figura 1B). Na primeira avaliação as diferenças da MSPA foram menos acentuadas, variando de 1.005 a $3.710 \mathrm{~kg} \mathrm{ha}^{-1}$, com 27 e 192 $\mathrm{kg} \mathrm{ha}^{-1}$ de $\mathrm{N}$ disponível, respectivamente. Posteriormente, a diferenciação entre os tratamentos tornou-se mais acentuada em virtude da maior demanda de $\mathrm{N}$ pela planta, com maiores respostas à disponibilidade de N. Aos 99 DAE, estádio de grão dentado, a produção de MSPA foi de 8.725 e de $39.710 \mathrm{~kg} \mathrm{ha}^{-1}$, com 27 e $190 \mathrm{~kg} \mathrm{ha}^{-1}$ de $\mathrm{N}$ disponível, respectivamente. Nesta mesma região França et al. (1999) alcançaram produções de 28.662 $\mathrm{kg} \mathrm{ha}^{-1}$ de MSPA, no estádio de grãos completamente dentados, porém com aplicação de $140 \mathrm{~kg} \mathrm{ha}^{-1}$ de $\mathrm{N}$ mineral e Bergonci et al. (2001) entre os anos agrícolas de 1993/94 a 1996/97, obtiveram produção de massa seca da parte aérea de milho irrigado, mínina de $22.201 \mathrm{~kg} \mathrm{ha}^{-1}$ e máxima de $27.838 \mathrm{~kg} \mathrm{ha}^{-1}$.

$\mathrm{O}$ acúmulo de MSPA foi mais acentuado no final do ciclo, nos níveis mais elevados de $\mathrm{N}$ disponível. Nos níveis de menor disponibilidade a resposta de acúmulo de MSPA sugere um padrão aproximadamente linear, ascendente ao longo do ciclo da cultura enquanto nos níveis mais elevados esta resposta apresenta tendência à saturação, com valor máximo estimado acima de $35.000 \mathrm{~kg} \mathrm{ha}^{-1}$ (Figura 1B).

Para Lopes et al. (2009), o maior valor de fitomassa seca total ocorreu aos $90 \mathrm{DAE}$ em plantio convencional e aos 105 DAE em plantio direto. Após essas datas, nos dois sistemas o acúmulo de fitomassa seca total praticamente cessou, apesar de haver crescimento significativo das espigas porém houve, também, queda de folhas e da massa nos colmos. A queda na fitomassa seca de folha ocorreu em razão do início da senescência enquanto a queda na massa dos colmos deve estar associada à transferência de carboidratos para outros órgãos em crescimento, especificamente as espigas.

\section{Nitrogênio absorvido pelo milho}

A partir da emergência do milho a absorção de $\mathrm{N}$ foi ascendente em toda a faixa de disponibilidade de $\mathrm{N}$, atingindo o valor máximo observado de 296,44 $\mathrm{kg} \mathrm{ha}^{-1}$ de $\mathrm{N}$ aos 74 DAE (grão leitoso) com $192 \mathrm{~kg}$ de $\mathrm{N}$ disponível. A partir deste valor máximo observou-se redução de $\mathrm{N}$ na biomassa (Tabela 2 e Figura 1C ). A maior absorção de $\mathrm{N}$ neste estádio diverge de Fornasieri Filho (1992), cuja maior demanda de $\mathrm{N}$ ocorreu cerca de duas a três semanas antes do florescimento e no florescimento, enquanto a redução após os 82 DAE é esperada 
Tabela 2. Índice de área foliar, massa seca da parte aérea e nitrogênio $(\mathrm{N})$ absorvido pelo milho em função do nitrogênio disponível

\begin{tabular}{|c|c|c|c|c|c|}
\hline $\begin{array}{l}\text { N disponível } \\
\left(\mathrm{kg} \mathrm{ha}^{-1}\right)\end{array}$ & $\begin{array}{c}52 \text { DAE } \\
\text { Doze folhas }^{(1)}\end{array}$ & $\begin{array}{c}65 \text { DAE } \\
\text { Polinização }{ }^{(1)}\end{array}$ & $\begin{array}{c}4 \text { DAE } \\
\text { Grão leitoso }^{(1)}\end{array}$ & $\begin{array}{c}82 \text { DAE } \\
\text { Grão pastoso }\end{array}$ & $\begin{array}{c}99 \text { DAE } \\
\text { Grão dentado }{ }^{(1)}\end{array}$ \\
\hline \multicolumn{6}{|c|}{ Índice de área foliar } \\
\hline 27 & $1,29 \pm 0,06$ & $1,64 \pm 0,32$ & $1,35 \pm 0,18$ & $0,90 \pm 0,24$ & $1,07 \pm 0,13$ \\
\hline 50 & $2,56 \pm 0,47$ & $2,67 \pm 0,35$ & $2,21 \pm 0,13$ & $1,84 \pm 0,16$ & $1,57 \pm 0,40$ \\
\hline 55 & $2,36 \pm 0,42$ & $2,24 \pm 0,47$ & $2,35 \pm 0,29$ & $1,58 \pm 0,18$ & $1,40 \pm 0,35$ \\
\hline 72 & $2,29 \pm 0,36$ & $2,86 \pm 0,08$ & $2,22 \pm 0,18$ & $2,08 \pm 0,30$ & $1,54 \pm 0,20$ \\
\hline 95 & $2,85 \pm 0,20$ & $3,50 \pm 0,21$ & $3,30 \pm 0,25$ & $2,89 \pm 0,45$ & $2,27 \pm 0,20$ \\
\hline 100 & $2,71 \pm 0,31$ & $3,43 \pm 0,10$ & $3,13 \pm 0,32$ & $2,92 \pm 0,33$ & $2,58 \pm 0,17$ \\
\hline 123 & $2,93 \pm 0,12$ & $3,85 \pm 0,04$ & $3,47 \pm 0,22$ & $3,12 \pm 0,37$ & $2,50 \pm 0,45$ \\
\hline 145 & $3,22 \pm 0,11$ & $3,75 \pm 0,19$ & $3,76 \pm 0,11$ & $3,35 \pm 0,20$ & $3,10 \pm 0,44$ \\
\hline 147 & $3,12 \pm 0,04$ & $3,68 \pm 0,12$ & $3,96 \pm 0,23$ & $3,59 \pm 0,28$ & $3,44 \pm 0,41$ \\
\hline 168 & $3,30 \pm 0,13$ & $4,05 \pm 0,12$ & $3,84 \pm 0,24$ & $3,78 \pm 0,35$ & $3,49 \pm 0,23$ \\
\hline 190 & $3,44 \pm 0,27$ & $4,36 \pm 0,29$ & $4,19 \pm 0,33$ & $3,98 \pm 0,18$ & $3,26 \pm 0,28$ \\
\hline 192 & $3,63 \pm 0,24$ & $4,41 \pm 0,18$ & $4,37 \pm 0,06$ & $3,99 \pm 0,22$ & $3,63 \pm 0,15$ \\
\hline \multicolumn{6}{|c|}{ Massa seca da parte aérea $\left(\mathrm{kg} \mathrm{ha}^{-1}\right)$} \\
\hline 27 & $1.005 \pm 193$ & $3.901 \pm 207$ & $5.783 \pm 157$ & $4.725 \pm 390$ & $8.725 \pm 2.689$ \\
\hline 50 & $2.618 \pm 206$ & $10.030 \pm 1.637$ & $12.623 \pm 2.662$ & $7.971 \pm 1.575$ & $18.551 \pm 5.156$ \\
\hline 55 & $1.942 \pm 682$ & $6.420 \pm 866$ & $11.087 \pm 1.610$ & $12.507 \pm 1.310$ & $16.449 \pm 3.291$ \\
\hline 72 & $1.942 \pm 351$ & $8.898 \pm 1.795$ & $12.478 \pm 565$ & $15.232 \pm 404$ & $14.348 \pm 1.292$ \\
\hline 95 & $2.986 \pm 105$ & $12.328 \pm 1.067$ & $17.638 \pm 654$ & $15.899 \pm 978$ & $28.739 \pm 4.631$ \\
\hline 100 & $2.531 \pm 146$ & $11.328 \pm 1.958$ & $15.362 \pm 2.813$ & $17.319 \pm 392$ & $28.377 \pm 1.069$ \\
\hline 123 & $2.754 \pm 174$ & $13.357 \pm 1.130$ & $16.275 \pm 2.324$ & $18.855 \pm 766$ & $27.493 \pm 1.727$ \\
\hline 145 & $3.208 \pm 134$ & $14.219 \pm 957$ & $19.174 \pm 1.208$ & $20.145 \pm 283$ & $34.377 \pm 1.616$ \\
\hline 147 & $3.111 \pm 149$ & $13.668 \pm 1.053$ & $20.696 \pm 1.092$ & $22.377 \pm 1.290$ & $33.333 \pm 2.473$ \\
\hline 168 & $3.382 \pm 318$ & $14.781 \pm 1.913$ & $19.855 \pm 526$ & $24.290 \pm 790$ & $36.884 \pm 3.159$ \\
\hline 190 & $3.643 \pm 269$ & $16.621 \pm 1.781$ & $21.478 \pm 1.348$ & $25.043 \pm 1.267$ & $39.710 \pm 6.030$ \\
\hline 192 & $3.710 \pm 398$ & $15.213 \pm 1.496$ & $23.928 \pm 2.115$ & $28.087 \pm 911$ & $33.014 \pm 2.696$ \\
\hline \multicolumn{6}{|c|}{ Nitrogênio absorvido na matéria seca $\left(\mathrm{kg} \mathrm{ha}^{-1}\right)$} \\
\hline 27 & $12,27 \pm 1,68$ & $28,52 \pm 5,07$ & $41,13 \pm 7,61$ & $16,15 \pm 3,34$ & $18,97 \pm 2,69$ \\
\hline 50 & $35,20 \pm 3,26$ & $74,61 \pm 20,43$ & $87,99 \pm 27,62$ & $30,83 \pm 7,02$ & $42,11 \pm 23,00$ \\
\hline 55 & $24,97 \pm 9,29$ & $42,85 \pm 7,25$ & $63,13 \pm 18,68$ & $48,59 \pm 7,41$ & $28,63 \pm 6,95$ \\
\hline 72 & $30,30 \pm 7,89$ & $68,58 \pm 12,17$ & $83,48 \pm 10,10$ & $67,82 \pm 8,62$ & $30,07 \pm 3,74$ \\
\hline 95 & $52,92 \pm 3,47$ & $131,30 \pm 16,27$ & $178,37 \pm 5,47$ & $80,79 \pm 6,83$ & $105,56 \pm 32,96$ \\
\hline 100 & $46,27 \pm 2,46$ & $140,38 \pm 30,60$ & $135,42 \pm 36,85$ & $85,49 \pm 10,69$ & $88,73 \pm 9,04$ \\
\hline 123 & $60,81 \pm 3,91$ & $161,51 \pm 15,52$ & $168,91 \pm 35,02$ & $118,87 \pm 19,85$ & $81,11 \pm 5,08$ \\
\hline 145 & $71,48 \pm 4,55$ & $178,17 \pm 19,17$ & $224,87 \pm 24,41$ & $139,12 \pm 18,41$ & $135,91 \pm 20,80$ \\
\hline 147 & $67,25 \pm 4,19$ & $200,24 \pm 17,64$ & $244,06 \pm 30,23$ & $160,23 \pm 9,78$ & $165,47 \pm 34,22$ \\
\hline 168 & $64,96 \pm 5,66$ & $213,72 \pm 43,38$ & $274,42 \pm 22,30$ & $197,91 \pm 14,11$ & $209,00 \pm 29,60$ \\
\hline 190 & $74,97 \pm 3,63$ & $244,70 \pm 37,92$ & $274,59 \pm 12,68$ & $206,69 \pm 24,86$ & $220,97 \pm 38,73$ \\
\hline 192 & $77,68 \pm 5,33$ & $223,52 \pm 51,08$ & 296,44 & $222,43 \pm 3,83$ & $208,05 \pm 24,97$ \\
\hline
\end{tabular}

DAE $=$ dias após emergência

Média \pm desvio padrão

(1) Escala proposta por Haway (1963)

(2) Estimado pela equação: $\mathrm{Nabs}=-6,92+1,58 \mathrm{Nd}$

e se deve à mobilização do $\mathrm{N}$ para o grão, queda de folhas e lixiviação de $\mathrm{N}$ das folhas e colmos senescentes. Vasconcelos et al. (1998), observaram decréscimo nos teores de $\mathrm{N}$ nas folhas e nos colmos, caracterizando a mobilização do nutriente para os grãos a partir do estádio de enchimento de grãos. Neste estádio os valores obtidos em sua pesquisa oscilaram entre 189 e $217 \mathrm{~kg} \mathrm{ha}^{-1}$ de $\mathrm{N}$ e no estádio de grão farináceo ficaram entre 175 e $246 \mathrm{~kg} \mathrm{ha}^{-1}$ de $\mathrm{N}$, para três cultivares avaliados.

$\mathrm{O}$ modelo linear de regressão entre $\mathrm{N}$ absorvido e $\mathrm{N}$ disponível durante o ciclo do milho, apresenta alta relação entre as variáveis (Tabela 3 ). Apesar de ter sido usado o valor de $\mathrm{k}_{3}$ igual a 0,75 para o cálculo do $\mathrm{N}$ disponível na presente pesquisa, na avaliação aos 65 DAE (floração plena), a inclinação da reta (coeficiente b) foi de 1,30, indicando maior disponibilidade de N do que a estimada pela equação sugerida por Amado (1997), no mesmo estádio de desenvolvimento. Também na pesquisa conduzida por Fernandes (1998), e a avaliação realizada no período de floração, a inclinação da reta foi aproximadamente igual a 1 demonstrando que para cada $\mathrm{kg}$ de $\mathrm{N}$ disponível estimado ocorreu absorção de $1 \mathrm{~kg}$ de $\mathrm{N}$ na fitomassa. Esta diferença decorre, provavelmente, da maior disponibilidade hídrica no presente estudo, conforme já mencionado, o que deve ter influenciado sua disponibilidade (maior $\mathrm{k}_{1}, \mathrm{k}_{2}, \mathrm{e} \mathrm{k}_{3}$ ) e absorção, que é altamente dependente do teor de água no solo (Villas-Bôas et al., 2005).

Valores máximos de $\mathrm{N}$ absorvido pelo milho com a disponibilidade de $190 \mathrm{~kg} \mathrm{ha}^{-1}$ de $\mathrm{N}$ observado e estimado com base nos modelos de regressão linear aos 52, 65, 74, 82, 99 e 160 (grãos) DAE (Tabela 3), são apresentados na Figura 2. Aos 99 DAE, dos $221 \mathrm{~kg} \mathrm{ha}^{-1}$ de $\mathrm{N}$ absorvido (Tabela 2), $96 \mathrm{~kg} \mathrm{ha}^{-1}$ de $\mathrm{N}$ estavam presentes na espiga aumentando este valor para $106 \mathrm{~kg} \mathrm{ha}^{-1}$ aos 160 DAE (grão seco), Tabela 4 e Figura 2. 
A.
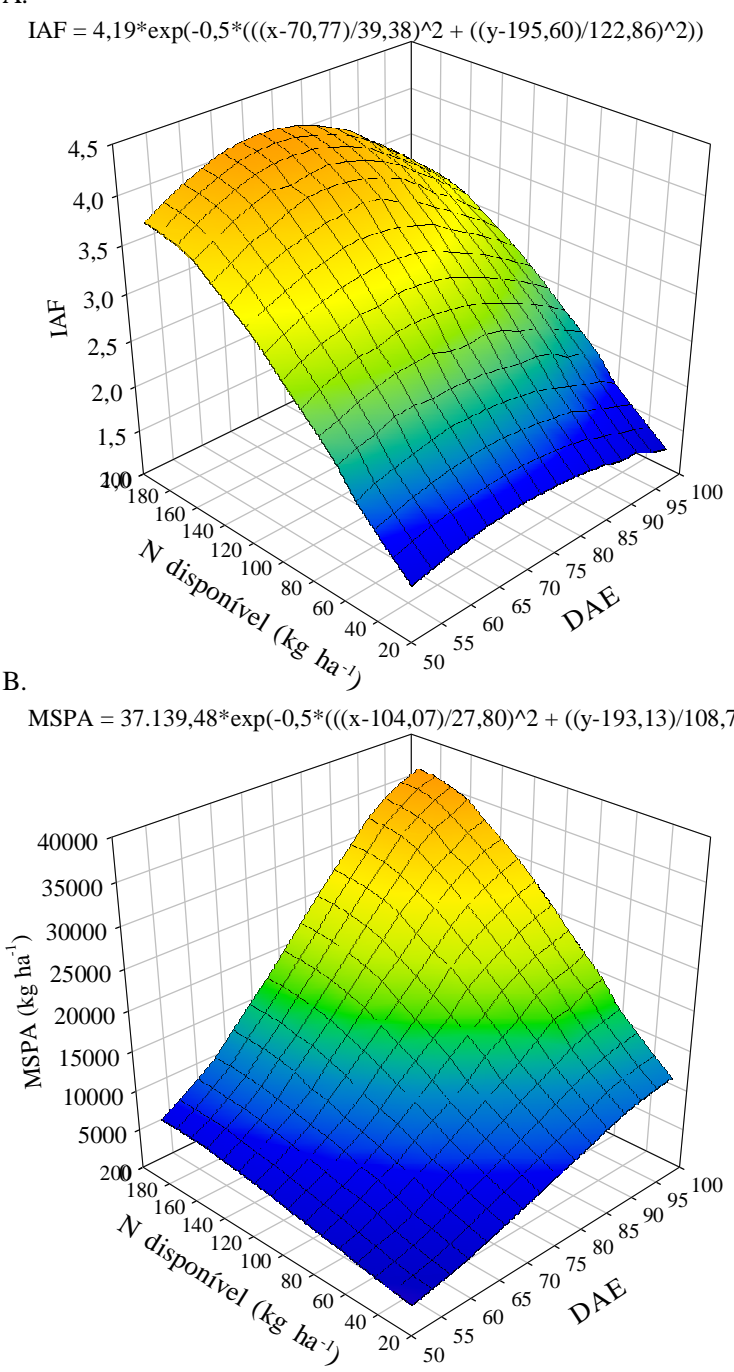

C.

$\mathrm{N}$ absorvido $=279,69 * \exp \left(-0,5 *\left(((\mathrm{x}-79,63) / 21,71)^{\wedge} 2+((\mathrm{y}-219,22) / 94,76)^{\wedge} 2\right)\right)$

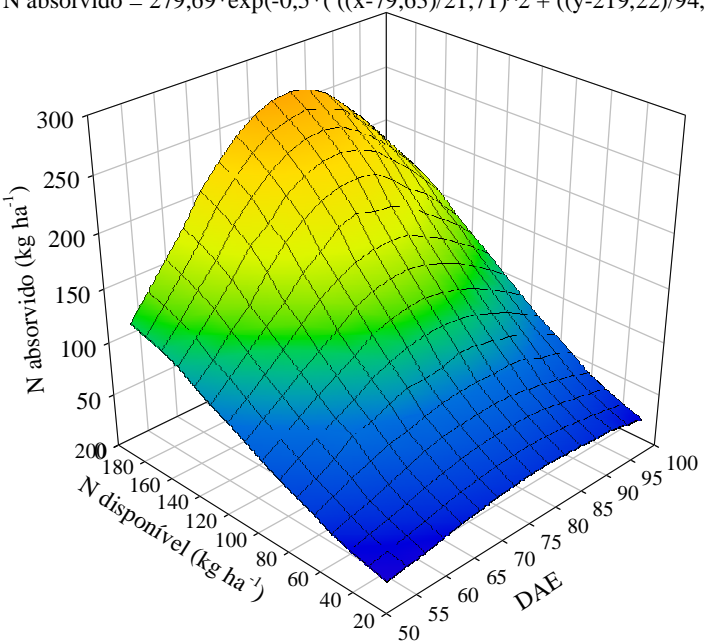

Figura 1. Índice de área foliar - IAF $(A)$, massa seca da parte aérea - MSPA (B) e nitrogênio absorvido (C) em função do $\mathrm{N}$ disponível ao milho e de dias após a emergência (DAE)

Considerando a quantidade máxima de $\mathrm{N}$ na massa seca da parte aérea do milho, que ocorreu aos 74 DAE (Tabela 2) e o rendimento obtido (Tabela 4 ), observa-se que a conversão de
$\mathrm{N}$ absorvido em grão produzido, $\mathrm{kg}$ de grãos $/ \mathrm{kg} \mathrm{N}$ absorvido variou entre 30 e 50 e a exportação de N para o grão ((N grãos/ $\mathrm{N}$ absorvidos aos $74 \mathrm{DAE}) * 100$ ) foi de aproximadamente $40 \%$. Para Vasconcelos et al. (1998), o híbrido BR 201 apresentou uma conversão do $\mathrm{N}$ assimilado em grãos de $50 \mathrm{~kg}$ de grãos por kg de $\mathrm{N}$ e exportação de $72 \%$ do total acumulado e, para o híbrido BR 106, a conversão foi de $39 \mathrm{~kg}$ de grãos por kg de N e a exportação de $66 \%$.

Tabela 3. Equações de regressão entre o $\mathrm{N}$ absorvido ( $\mathrm{N}$ abs) e o $\mathrm{N}$ disponível ( $\mathrm{N} \mathrm{d}$ ) para os períodos de 52, 65, 74, 82, 99 e160 dias após a emergência do milho (DAE)

\begin{tabular}{ll} 
Equação & $\mathbf{R}^{2}$ \\
$\mathrm{Nabs}^{1}{ }_{52 \mathrm{DAE}}=9,48+0,37 \mathrm{Nd}$ & 0,92 \\
$\mathrm{Nabs}^{1}{ }_{65} \mathrm{DAE}=-5,15+1,30 \mathrm{Nd}$ & 0,96 \\
$\mathrm{Nabs}^{1}{ }^{74 \mathrm{DAE}}=-6,92+1,58 \mathrm{Nd}$ & 0,95 \\
$\mathrm{Nabs}^{1}{ }_{82} \mathrm{DAE}=-27,78+1,25 \mathrm{Nd}$ & 0,98 \\
$\mathrm{Nabs}^{1}{ }_{99}$ DAE $=-36,31+1,30 \mathrm{Nd}$ & 0,92 \\
$\mathrm{Nabs}^{2}{ }_{99}$ DAE $=-23,86+0,77 \mathrm{Nd}$ & 0,92 \\
$\mathrm{Nabs}^{3}{ }_{160} \mathrm{DAE}=-1,39+0,58 \mathrm{Nd}$ & 0,95 \\
\hline
\end{tabular}

Tabela 4. Teor de nitrogênio ( $\mathrm{N}$ ) na fol ha índice, nitrogênio absorvido nos grãos e rendimento de grãos de milho em função do nitrogênio disponível

\begin{tabular}{|c|c|c|c|}
\hline \multirow{2}{*}{$\begin{array}{c}\mathrm{N} \\
\text { disponível } \\
\left(\mathrm{kg} \mathrm{ha}^{-1}\right)\end{array}$} & \multirow{2}{*}{$\begin{array}{c}\text { Teor de } \\
\mathrm{N} \text { na folha } \\
\text { índice (\%) }\end{array}$} & $\begin{array}{l}\mathrm{N} \text { absorvido } \\
\text { nos grãos }\end{array}$ & $\begin{array}{l}\text { Rendimento } \\
\text { de grãos }\end{array}$ \\
\hline & & \multicolumn{2}{|c|}{$\left(\mathrm{kg} \mathrm{ha}^{-1}\right)$} \\
\hline 27 & $1,19 \pm 0,10$ & $13,23 \pm 2,38$ & $1.425 \pm 289$ \\
\hline 50 & $1,23 \pm 0,09$ & $27,61 \pm 5,42$ & $3.437 \pm 993$ \\
\hline 55 & $1,17 \pm 0,03$ & $26,15 \pm 2,86$ & $2.872 \pm 103$ \\
\hline 72 & $1,64 \pm 0,09$ & $32,23 \pm 2,60$ & $3.618 \pm 203$ \\
\hline 95 & $2,17 \pm 0,04$ & $67,99 \pm 5,38$ & $5.982 \pm 318$ \\
\hline 100 & $1,56 \pm 0,11$ & $64,83 \pm 7,46$ & $6.699 \pm 427$ \\
\hline 123 & $2,31 \pm 0,02$ & $60,45 \pm 8,45$ & $6.565 \pm 789$ \\
\hline 145 & $2,29 \pm 0,12$ & $79,39 \pm 7,90$ & $7.212 \pm 913$ \\
\hline 147 & $2,26 \pm 0,23$ & $92,43 \pm 14,96$ & $8.158 \pm 1.089$ \\
\hline 168 & $2,53 \pm 0,05$ & $86,68 \pm 7,55$ & $7.780 \pm 570$ \\
\hline 190 & $2,56 \pm 0,07$ & $106,04 \pm 20,44$ & $8.507 \pm 1.248$ \\
\hline 192 & $2,49 \pm 0,09$ & $112,54 \pm 19,28$ & $8.924 \pm 1.472$ \\
\hline
\end{tabular}

\section{Rendimento de grãos de milho}

Os teores de nitrogênio na folha índice variaram entre $1,17 \mathrm{e}$ $2,17 \%$ com $\mathrm{N}$ disponível entre 27 e $100 \mathrm{~kg} \mathrm{ha}^{-1}$ e entre 2,26 e $2,56 \%$ com $\mathrm{N}$ disponível entre 123 e $192 \mathrm{~kg} \mathrm{ha}^{-1}$ (Tabela 4). Considerando que as concentrações de $\mathrm{N}$ total na folha índice são indicadores de um suprimento adequado de $\mathrm{N}$ para o milho, os tratamentos com disponibilidade de $\mathrm{N}$ de até $100 \mathrm{~kg} \mathrm{ha}^{-1}$ estariam sendo insuficientes à cultura; no entanto, os teores de $\mathrm{N}$ constatados nos tratamentos com $\mathrm{N}$ disponível acima de $123 \mathrm{~kg} \mathrm{ha}^{-1}$ estariam adequados, aproximando-se das concentrações de $\mathrm{N}$ total na folha índice, obtidas por Ceretta et al. (1994), que variaram de 2,21 a 2,75\% na cultura do milho.

$\mathrm{O}$ rendimento de grãos de milho em função do teor de $\mathrm{N}$ na folha índice (Figura 3B e Tabela 4) demonstra que teores de N na folha índice de aproximadamente $1,25 \%$ possibilitaram rendimentos em torno de $3.000 \mathrm{~kg} \mathrm{ha}^{-1}$, enquanto teores entre 2,20 e $2,60 \%$, entre 6.000 e $9.000 \mathrm{~kg} \mathrm{ha}^{-1}$. Resultados na mesma amplitude obtiveram Teixeira et al. (1994), para os quais um teor de $\mathrm{N}$ na folha índice de $2,24 \%$ correspondeu a rendimentos 


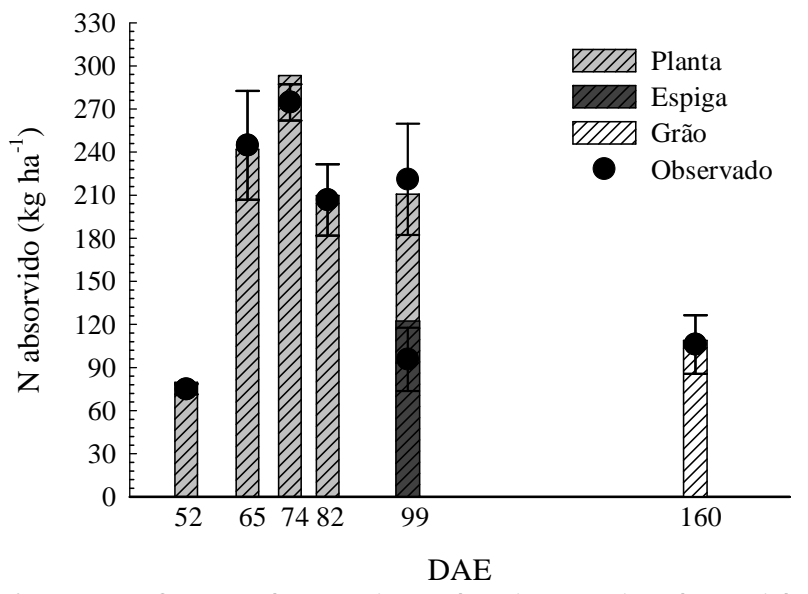

Figura 2. Conteúdo máximo de nitrogênio absorvido pelo milho observado (com desvio padrão) e estimado pelo modelo de regressão linear (barras) com $190 \mathrm{~kg} \mathrm{ha}^{-1}$ de $\mathrm{N}$ disponível, aos 52, 65, 74, 82, 99 e 160 dias após emergência-DAE

máximos de milho, entre 7.150 e $7.330 \mathrm{~kg} \mathrm{ha}^{-1}$. Para eles, a significância dos coeficientes de determinação entre o teor de $\mathrm{N}$ na folha índice e o rendimento de milho, indica a dependência do rendimento em relação à disponibilidade de N. Segundo Ferreira et al. (2001) a melhor característica para ser utilizada como índice de diagnose nutricional e de produção de grãos foi o teor de $\mathrm{N}$ orgânico aos $45 \mathrm{DAE}$ (antes do pendoamento) utilizando-se, na análise química, a última folha completamente aberta e a composição mineral dos grãos apresentou, em geral, alta correlação positiva com a composição mineral das folhas, fato constatado aos $63 \mathrm{DAE}$.

$\mathrm{O}$ rendimento de grãos de milho está diretamente influenciado por variações na disponibilidade de $\mathrm{N}$ (Figura 3C e Tabela 4). O menor rendimento foi de $1.425 \mathrm{~kg} \mathrm{ha}^{-1} \mathrm{com} 27 \mathrm{~kg}$ ha $^{-1}$ de $\mathrm{N}$ disponível (A/M $0 \mathrm{~N}$ ), uma absorção máxima pela planta de 41,13 $\mathrm{kg} \mathrm{ha}^{-1}$ de N, que ocorreu aos $74 \mathrm{DAE}$ (grão leitoso), Tabela 2. Rendimentos entre $7.200 \mathrm{e} 8.500 \mathrm{~kg} \mathrm{ha}^{-1}$ foram obtidos com 145, 147, 168 e $190 \mathrm{~kg} \mathrm{ha}^{-1}$ de $\mathrm{N}$ disponível (E/M $120 \mathrm{~N}, \mathrm{~A}+\mathrm{E} / \mathrm{M}+\mathrm{C} 120 \mathrm{~N}, \mathrm{~A} / \mathrm{M} 180 \mathrm{~N}$ e E/M $180 \mathrm{~N}$, respectivamente) e com uma absorção máxima de $\mathrm{N}$ entre $225 \mathrm{e}$ $275 \mathrm{~kg} \mathrm{ha}^{-1}$.

Tendência de rendimento de grãos de milho mais elevado nos sistemas $\mathrm{A}+\mathrm{E} / \mathrm{M}+\mathrm{C}$ e $\mathrm{E} / \mathrm{M}$, com dose de $\mathrm{N}$ mineral menor em relação ao sistema $\mathrm{A} / \mathrm{M}$, também foi observada neste mesmo experimento, por Lovato (2001) e Amado et al. (2000). Segundo Lovato et al. (2004), no sistema A/M, sem N mineral, no qual o balanço de $\mathrm{N}$ foi negativo, houve tendência de redução de rendimento de 1985/86 a 1997/98 enquanto nos sistemas com leguminosas, nos quais o balanço de $\mathrm{N}$ foi positivo, deu-se aumento gradual de rendimento entre o início do experimento e o $13^{\circ}$ ano. Para Weber \& Mielniczuk (2009), na ausência de adubação nitrogenada mineral os sistemas com leguminosas apresentaram maiores rendimentos de grãos na média do período 1984-2005 e, com a aplicação de adubação nitrogenada mineral na cultura do milho, o aumento no rendimento de grão foi notório.

O rendimento máximo de grãos, $8.920 \mathrm{~kg} \mathrm{ha}^{-1}$, foi obtido com a disponibilidade de $\mathrm{N}$ de $192 \mathrm{~kg} \mathrm{ha}^{-1}(\mathrm{~A}+\mathrm{E} / \mathrm{M}+\mathrm{C} 180 \mathrm{~N})$ e com
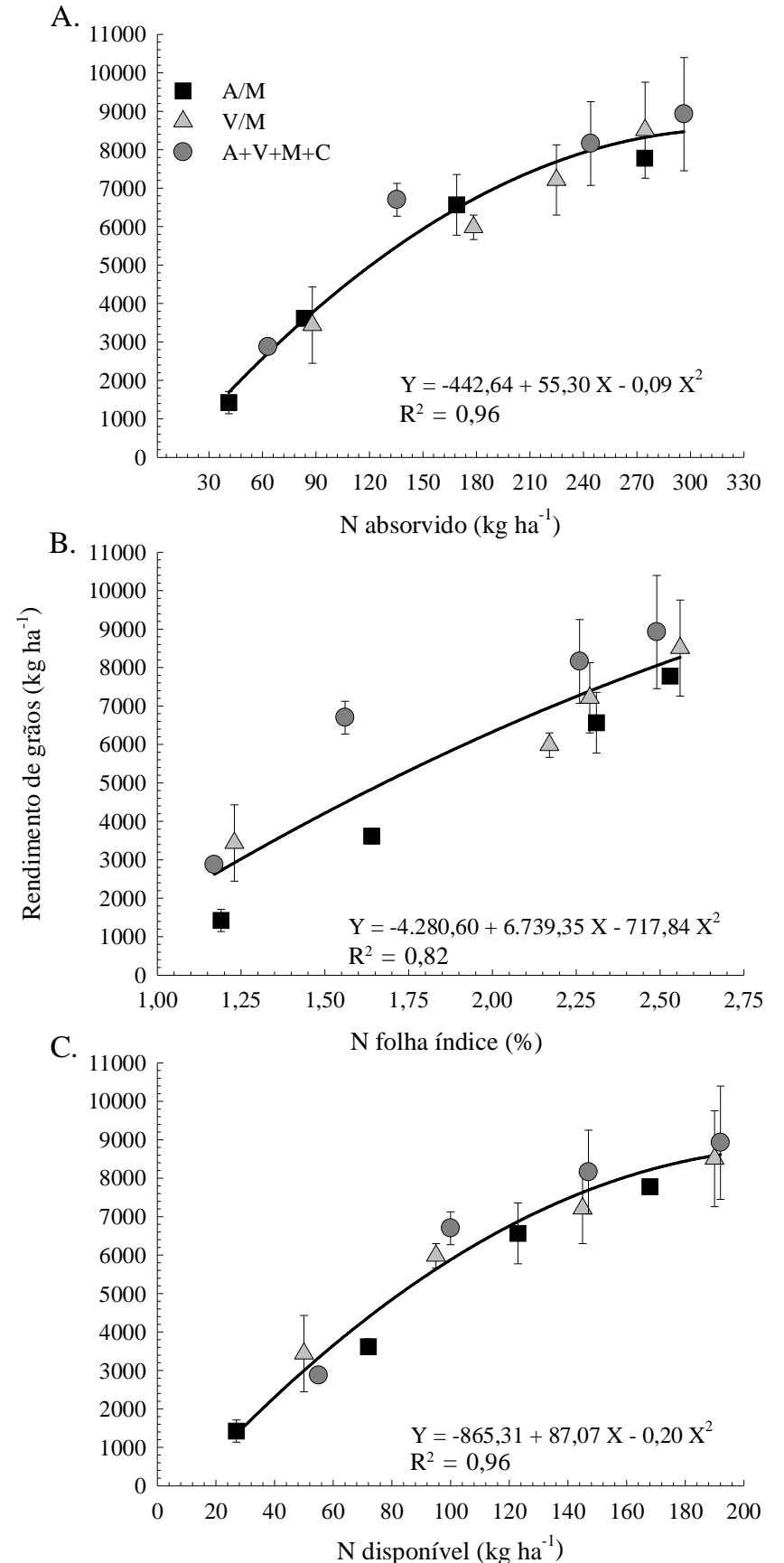

Figura 3. Relação entre rendimento de grãos de milho e $\mathrm{N}$ absorvido aos 74 dias após a emergência (A), teor de $\mathrm{N}$ na folha índice (B) e $\mathrm{N}$ disponível (C), em diferentes sistemas de cultura ( $\mathrm{A} / \mathrm{M}=\mathrm{A}$ veia/Milho; $\mathrm{V} / \mathrm{M}=\mathrm{Vica}$ / Milho e $A+V / M+C=$ Aveia+Vica/Milho+ Caupi)

uma absorção de $296 \mathrm{~kg} \mathrm{ha}^{-1}$ de N. Com a aplicação de N mineral verificou-se aumento expressivo de rendimento do milho entre 1985/86 e 1997/98, atingindo rendimentos superiores a 9.000 $\mathrm{kg} \mathrm{ha}^{-1}$ nesta última safra (Lovato et al., 2004). Também na Estação Experimental da UFRGS, Conte et al. (2009) obtiveram um rendimento médio de grãos de $8,351 \mathrm{~kg} \mathrm{ha}^{-1}$ na presença de irrigação, sendo esta utilizada de forma suplementar quando a pluviosidade era insuficiente ou não ocorreu, como verificado em boa parte do ciclo do milho neste experimento. Beleze et al. (2003) obtiveram, trabalhando com o mesmo híbrido, uma 
produção de grãos superior a $8.000 \mathrm{~kg} \mathrm{ha}^{-1}$, porém com adubação em cobertura de $250 \mathrm{~kg} \mathrm{ha}^{-1}$ da fórmula $25-0-5$ (N-P-K).

Considerando o teor de $\mathrm{N}$ na folha índice, independente do sistema de cultura, na dose de $120 \mathrm{~kg} \mathrm{ha}^{-1}$ de $\mathrm{N}$ mineral os valores ficaram entre 2,26 e 2,31\% de N, com disponibilidade de $\mathrm{N}$ entre 123 e $147 \mathrm{~kg} \mathrm{ha}^{-1}$ (tratamentos A/M $180 \mathrm{~N}, \mathrm{E} / \mathrm{M} 120$ $\mathrm{N}$ e $\mathrm{A}+\mathrm{E} / \mathrm{M}+\mathrm{C} 120 \mathrm{~N}$ ). Esses valores são superiores ao teor de $\mathrm{N}$ crítico na folha índice do milho determinado por Cerrato \& Blackmer (1991), que é de 2,1\%; os autores consideram este parâmetro uma ferramenta capaz de detectar deficiências e também consumo de luxo, visto que altos teores de $\mathrm{N}$ não resultam em aumentos no rendimento de grãos. Desta forma e em função dos resultados obtidos, pode-se concluir que a dose de $120 \mathrm{~kg} \mathrm{ha}^{-1}$ de $\mathrm{N}$ é a mais recomendada nas condições deste experimento, sobretudo nos sistemas com a presença de leguminosa. Raij \& Cantarella (1996) também recomendam aplicar $120 \mathrm{~kg} \mathrm{ha}^{-1}$ de $\mathrm{N}$ para obter produtividade entre $8.000 \mathrm{e}$ $10.000 \mathrm{~kg} \mathrm{ha}^{-1}$ de grãos. Igualmente para Araújo et al. (2004), a quantidade máxima de $\mathrm{N}$ no grão foi obtida com a dose de 120 $\mathrm{kg} \mathrm{ha}^{-1}$ de N. Cruz et al. (2008) concluíram que em condições climáticas normais e solo com fertilidade satisfatória a utilização de $120 \mathrm{~kg} \mathrm{ha}^{-1}$ de $\mathrm{N}$ permite ao agricultor retorno econômico da adubação nitrogenada. Para Leite et al. (2009), em sistema de PD a maior produtividade, estimada de acordo com o ponto de máxima eficiência técnica da equação ajustada, foi obtida com a dose $124 \mathrm{~kg} \mathrm{ha}^{-1}$ de $\mathrm{N}$, que correspondeu a $6.480 \mathrm{~kg} \mathrm{ha}^{-1}$, e a dose econômica, obtida por meio da comparação da equação de rendimento e de custo, foi de $95,9 \mathrm{~kg} \mathrm{ha}^{-1}$, resultando em uma produção de grãos de $6.450 \mathrm{~kg} \mathrm{ha}^{-1}$.

O rendimento de grãos de milho apresentou alta dependência em relação à quantidade de $\mathrm{N}$ absorvido aos $74 \mathrm{DAE}$, com coeficiente de determinação de 0,96 (Figura 3A), ao teor de N na folha índice, com $\mathrm{r}^{2}$ de 0,82 (Figura $3 \mathrm{~B}$ ) e ao nitrogênio disponível, com $r^{2}$ de 0,96 (Figura 3C) indicando que uma fração significativa da variação do rendimento pode ser explicada através dessas variáveis porém, devido à maior simplicidade de cálculo e à não necessidade de análises laboratoriais, que demandam custos com materiais e mão-de-obra, a estimativa do rendimento de grãos em função do $\mathrm{N}$ disponível ao milho seria mais recomendada, sendo esta dependente do $\mathrm{N}$ total do solo, do sistema de cultura e da dose de $\mathrm{N}$ mineral. A dependência do rendimento de grãos ao $\mathrm{N}$ disponível também foi demonstrada por Fernandes (1998), que salientou a amplitude de resposta nos tratamentos sem aplicação de $\mathrm{N}$ mineral, especialmente nos sistemas de cultura com leguminosas.

Os resultados obtidos evidenciam que a disponibilidade de $\mathrm{N}$ afeta o crescimento vegetativo condicionando, primeiramente, a variação de IAF. Sendo o índice de área foliar uma variável de crescimento relacionada ao processo de interceptação da radiação solar e assimilação de carbono pela cultura, explica-se o fato dos tratamentos com maior disponibilidade de $\mathrm{N}$ apresentarem maior acúmulo de MSPA, maior absorção de $\mathrm{N}$ e maior rendimento de grãos de milho, permitindo supor que a influência dos sistemas de cultura sobre o rendimento de milho pode ser atribuída, em grande parte, ao efeito desses sistemas no suprimento de $\mathrm{N}$.

\section{CONCLUSÕES}

1. A quantidade de nitrogênio disponível ao milho variou entre sistemas de cultura e doses de $\mathrm{N}$ mineral aplicadas enquanto os sistemas de cultura que incluem leguminosas disponibilizaram maiores quantidades de $\mathrm{N}$ em comparação com sistemas cultivados apenas com gramíneas.

2. Os sistemas de cultura ervilhaca/milho (E/M) e aveia + ervilhaca/milho + caupi $(\mathrm{A}+\mathrm{E} / \mathrm{M}+\mathrm{C})$ são equivalentes entre si e superiores em relação ao nitrogênio disponível no sistema aveia/milho (A/M); também, a maior absorção de $\mathrm{N}$ ocorre nos sistemas de cultura $\mathrm{E} / \mathrm{M}$ e $\mathrm{A}+\mathrm{E} / \mathrm{M}+\mathrm{C}$, em comparação com o sistema A/M, atingindo o valor máximo a 74 DAE (grão leitoso).

3. O índice de área foliar, a produção de massa seca da parte aérea, o $\mathrm{N}$ absorvido pela planta e o rendimento de grãos de milho, são influenciados pela disponibilidade de nitrogênio. Os sistemas de cultura com leguminosas, independente da dose de $\mathrm{N}$ mineral aplicada, proporcionam elevação das variáveis analisadas em comparação a sistemas com a presença apenas de gramíneas. A aplicação de $\mathrm{N}$ mineral aumenta esses atributos em todos os sistemas de cultura.

\section{Agradecimentos}

Ao Conselho Nacional de Desenvolvimento Científico e Tecnológico (CNPq), pela concessão de bolsa de doutorado ao primeiro autor; ao amigo e colega Pedro G. Pereira, Eng. Agr., M.Sc., pelo Programa de Pós-Graduação em Fitotecnia da UFRGS.

\section{LITERATURA CITADA}

Aita, C. Basso, C. J.; Ceretta, C. A.; Gonçalves, C. N.; Ros, C. O. da. Plantas de cobertura de solo como fontes de nitrogênio ao milho. Revista Brasileira de Ciência do Solo, v.25, p.157$165,2001$.

Amado, T. J. C. Disponibilidade de nitrogênio para o milho em sistemas de cultura e preparo do solo. Porto Alegre: UFRGS, 1997. 217p. Tese Doutorado

Amado, T. J. C.; Mielniczuk, J. Estimativa da adubação nitrogenada para o milho em sistemas de manejo e culturas de cobertura do solo. Revista Brasileira de Ciência do Solo, v.24, p.53-560, 2000.

Amado, T. J. C.; Mielniczuk, J.; Fernandes, S. B. V. Leguminosas e adubação mineral como fontes de nitrogênio pra o milho em sistemas de preparo do solo. Revista Brasileira de Ciência do Solo, v.24, p.179-189, 2000.

Araújo, L. A. N. de.; Fereira, M. E.; Cruz, M. C. P. da. Adubação nitrogenada na cultura do milho. Pesquisa Agropecuária Brasileira, v.39, p.771-777, 2004.

Arf, O.; Silva, L. S. da; Buzetti, S.; Alves, M. C.; Sá, M. E. de; Rodrigues, R. A. F.; Hernandez, F. B. T. Efeitos na cultura do trigo da rotação com milho e adubos verdes, na presença e na ausência de adubação nitrogenada. Bragantia, v.58, p.323-334, 1999. 
Assmann, T. S.; Ronzelli Júnior, P.; Assmann, A. L.; Koehler, H. S.; Sandini, I. Rendimento de milho em área de integração lavoura-pecuária sob o sistema plantio direto, em presença e ausência de trevo branco, pastejo e nitrogênio. Revista Brasileira de Ciência do Solo, v.27, p.675-683, 2003.

Beleze, J. R. F.; Zeoula, L. M.; Cecato, U.; Dian, P. H. M.; Martins, E. N., Falcão, A. J. da S. Avaliação de cinco híbridos de milho (Zea mays, L.) em diferentes estádios de maturação. 1. Produtividade, características morfológicas e correlações. Revista Brasileira de Zootecnia, v.32, p.529-537, 2003.

Bergamaschi, H.; Guadagnin, M. R.; Cardoso, L. S.; Silva, M. I. G. da. Clima da Estação Experimental da UFRGS (e região de abrangência). Porto Alegre: UFRGS, 2003. 77p.

Bergonci, J. I.; Bergamaschi, H.; Santos, A. O.; França, S.; Radin, B. . Eficiência da irrigação em rendimento de grãos e matéria seca de milho. Pesquisa Agropecuária Brasileira, v.36, n.7, p. 949-956, 2001.

Ceretta, C. A.; Aita, C.; Braida, J. A.; Pavinato, A. Salet, R. L. Fornecimento de nitrogênio por leguminosas na primavera para o milho em sucessão nos sistemas de cultivo mínimo e convencional. Revista Brasileira Ciência do Solo, v.18, p.215220, 1994

Cerrato, M. E.; Blackmer, A. M. Relationships between leaf nitrogen concentrations and the nitrogen status of of corn. Journal of Production Agriculture, v.4, p.525-531, 1991.

Conte, O.; Levien, R.; Trein, C. R.; Debiasi, H.; Mazurana, M. Rendimento do milho em diferentes condições físicas de solo e quantidade de resíduo na ausência ou na presença de irrigação. Ciência Rural, v.39, p.1059-1066, 2009.

Cruz, S. C. S.; Pereira, F. R. da S.; Santos, J. R.; Albuquerque, A. W. de; Pereira, R. G. Adubação nitrogenada para o milho cultivado em sistema plantio direto, no Estado de Alagoas. Revista Brasileira de Engenharia Agrícola e Ambiental, v.12, p.62-68, 2008.

EMBRAPA - Empresa Brasileira de Pesquisa Agropecuária. Centro Nacional de Pesquisa de Solos. Sistema brasileiro de classificação de solos. Rio de Janeiro: EMBRAPA, 1999. 412p.

Fernandes, S. B. V. Disponibilidade e eficiência de uso do nitrogênio pelo milho em sistemas de cultura. Porto Alegre: UFRGS, 1998. 137p. Tese Doutorado

Ferreira, A. C. de B.; Araújo, G. A. de A.; Pereira, P. R. G.; Cardoso, A. A. Características agronômicas e nutricionais do milho adubado com nitrogênio, molibdênio e zinco. Scientia Agricola, v.58, p.131-138, 2001.

Fornasieri Filho, D. A cultura do milho. Jaboticabal: FUNEB, 1992. 273p.

França, S. Efeitos da disponibilidade de nitrogênio e água na fotossíntese, crescimento e produção do milho, em diferentes sistemas de cultura. Porto Alegre: UFRGS, 2003. 170p. Tese Doutorado

França, S.; Bergamaschi, H.; Rosa, L. M. G. Modelagem de crescimento e rendimento de milho em função da radiação fotossinteticamente ativa e do acúmulo de graus-dia, com e sem irrigação. Revista Brasileira de Agrometeorologia, v.7, p.59-66, 1999.

Freud, R. J.; Littel, R. C.; Spector, P. C. SAS system for liner models. Cary: SAS Institute Inc., 1986. 210p.

Hanway, J. J. Growth stages of corn (Zea mays L.). Agronomy Journal, v.55, p.487-491, 1963.
Heinrichs, R.; Aita, C.; Amado, T. J. C.; Fancelli, A. L. Cultivo consorciado de aveia e ervilhaca: relação $\mathrm{C} / \mathrm{N}$ da fitomassa e produtividade do milho em sucessão. Revista Brasileira de Ciência do Solo, v.25, p.331-340, 2001.

Leite, L. F. C.; Cardoso, M. J.; Costa, D. B.; Freitas, R. de C. A. de; Ribeiro, V. Q.; Galvão, S. R. da S. Estoques de C e de Ne produtividade do milho sob sistemas de preparo e adubação nitrogenada em um Latossolo Vermelho-Amarelo do cerrado piauiense. Ciência Rural, v.39, n.9, p.2460-2466, 2009.

Lopes, J. P.; Machado, E. C.; Deuber, R.; Machado, R. S. Análise de crescimento e trocas gasosas na cultura de milho em plantio direto e convencional. Bragantia, v.68, p.839-848, 2009.

Lovato, T. Dinâmica do carbono e nitrogênio do solo afetada por preparos do solo, sistemas de cultura e adubo nitrogenado. Porto Alegre: UFRGS, 2001. 130p. Tese Doutorado

Lovato, T.; Mielniczuk, J.; Bayer, C.; Vezzani, F. Adição de carbono e nitrogênio e sua relação com os estoques no solo e com o rendimento do milho em sistemas de manejo. Revista Brasileira de Ciência do Solo, v.28, p. 175-187, 2004.

Raij, B. van; Cantarella, H. Milho para grãos e silagem. In: van Raij, B.; Cantarella, H.; Quaggio, J. A.; Furlani, A. M. C. (ed.). Recomendações de adubação e calagem para o Estado de São Paulo. 2.ed. Campinas: Instituto Agronômico, 1996. p.56-59. Boletim Técnico, 100

Silva, A. A da; Silva, P. R. F. da; Suhre, E.; Argenta, G.; Strieder, M. L.; Rambo, L. Sistemas de coberturas de solo no inverno e seus efeitos sobre o rendimento de grãos do milho em sucessão. Ciência Rural, v.37, p.928-935, 2007.

Souza, E. G.; Rocha, T.; Uribe-Opazo, M. A.; Nóbrega, L. H. P. Índices de vegetação no milho em função da hora do dia e da taxa de nitrogênio aplicada. Revista Brasileira de Engenharia Agrícola e Ambiental, v.13, p.865-872, 2009.

Tedesco, M. J.; Gianello, C.; Bissani, C. A. Análise de solo, plantas e outros materiais. 2.ed. Porto Alegre: UFRGS, 1995. 174p. Boletim Técnico de Solos, 5

Teixeira, L. A.; Testa, V. M.; Mielniczuk, J. Nitrogênio do solo, nutrição e rendimento de milho afetados por sistemas de cultura. Revista Brasileira de Ciência do Solo, v.18, p.207214, 1994.

Vasconcelos, C. A.; Viana, M. C.; Ferreira, J. J. Acúmulo de matéria seca e de nutrientes em milho cultivado no período de inverno-primavera. Pesquisa Agropecuária Brasileira, v.33, p.1835-1845, 1998.

Villas-Bôas, R. L.; Boaretto, A. E.; Godoy, L. J. G. de; Fernández, D. M. Recuperação do nitrogênio da mistura de uréia e sulfato de amônio por plantas de milho. Bragantia, v.64, p.263-272, 2005.

Weber, M. A.; Mielniczuk, J. Estoque e disponibilidade de nitrogênio no solo em experimento de longa duração. Revista Brasileira de Ciência do Solo, v.33, p.429-437, 2009.

Wolschick, D.; Carlesso, R.; Petry, M. T; Jadoski, S. O. Adubação nitrogenada na cultura do milho no sistema plantio direto em ano com precipitação pluvial normal e com "E1 Niño". Revista Brasileira de Ciência do Solo, v.27, p.461-468, 2003.

Zanatta, J. A. Estoque e labilidade do carbono em frações da matéria orgânica de um Argissolo afetado por sistemas de manejo. Porto Alegre: UFRGS, 2006. 113p. Dissertação Mestrado 